\title{
Gastric adenocarcinoma associated with adenomyoma of the stomach
}

\author{
C.R. Chapple, S. Muller and J. Newman
}

Departments of Surgery and Histopathology, East Birmingham Hospital, Bordesley Green East, Birmingham B9 $5 S T$ UK.

\begin{abstract}
Summary: We report a case of gastric adenomyoma contiguous with adenocarcinoma of the stomach. Although a similar association is well recognized in the duodenum, we believe this to be the first documented case in the stomach. We review the literature on adenomyomata and discuss the implications of this finding.

It would appear that glandular and cystic intramural lesions of the stomach are a heterogeneous group, and while there is a well established association between gastric carcinoma and gastritis cystica profunda, the same does not apply to gastric adenomyoma.
\end{abstract}

\section{Introduction}

Adenomyomata are uncommon benign gastric tumours, which occur in an intramural extramucosal position, usually in the gastric antrum or pylorus. ${ }^{1}$ They contain hypertrophied disordered smooth muscle bundles and a variety of epithelial elements ranging from simple glandular structures to Brunner's glands and pancreatic acini.

We report the previously undescribed occurrence of gastric adenocarcinoma with a contiguous adenomyoma.

\section{Case report}

A 55 year old man presented with a 10-month history of postprandial dyspeptic epigastric pain, relieved by antacids. He had suffered from general lethargy and had lost two stones in weight. There were no symptoms of pyloric obstruction and no other relevant medical history. On examination he was clinically anaemic (haemoglobin $6.0 \mathrm{~g} / \mathrm{dl}$ with a hypochromic microcytic picture), no supraclavicular lymph nodes were palpable and there were no intraabdominal masses. A barium meal demonstrated prepyloric shouldering with a deformed duodenal cap. Endoscopy demonstrated a prepyloric tumour which was confirmed on biopsy to be adenocarcinoma. A total gastrectomy with an oesophagojejun-

Correspondence: C.R. Chapple, B.S.c., F.R.C.S., Department of Urological Surgery, Middlesex Hospital, Mortimer Street, London W1, UK.

Accepted: 7 April 1988 ostomy Roux-en-Y was carried out. The patient made a good recovery but 2 years later developed obstructive jaundice due to enlarged lymph nodes at the porta hepatis.

Macroscopic examination of the surgical specimen revealed the pylorus to be diffusely infiltrated by an ulcerated tumour mass $6 \times 4 \mathrm{~cm}$ in size. Beneath and to one side of the tumour was a spongy, cystic area approximately $2 \mathrm{~cm}$ long, situated within the submucosa and extending through the main muscle coat to the serosa (Figure 1). Microscopic examination revealed the tumour to be a moderately differentiated mucinsecreting gastric adenocarcinoma of intestinal type, extending out to the serosa and with spread to submucosal lymphatics but not to regional lymph nodes. Random examination of the gastric mucosa away from the tumour demonstrated areas of gastritis and metaplasia but no dysplasia. Merging with the adenocarcinoma and ramifying throughout both the submucosa and muscularis propria and extending to the serosa were collections of dilated glands and cysts, lined with epithelium varying from flattened through cuboidal to columnar in type and showing intestinal metaplasia with goblet cells. Loose fibrous stroma surrounded the cysts and the majority were encircled by bundles of smooth muscle fibres and mature collagen (Figure 2). No differentiated heterogeneous epithelium, such as Brunner's glands or exocrine pancreas, was to be seen. Of special interest were areas of intracystic glandular epithelium demonstrating both architectural and cytological alteration amounting to carcinoma-in-situ, with frequent 


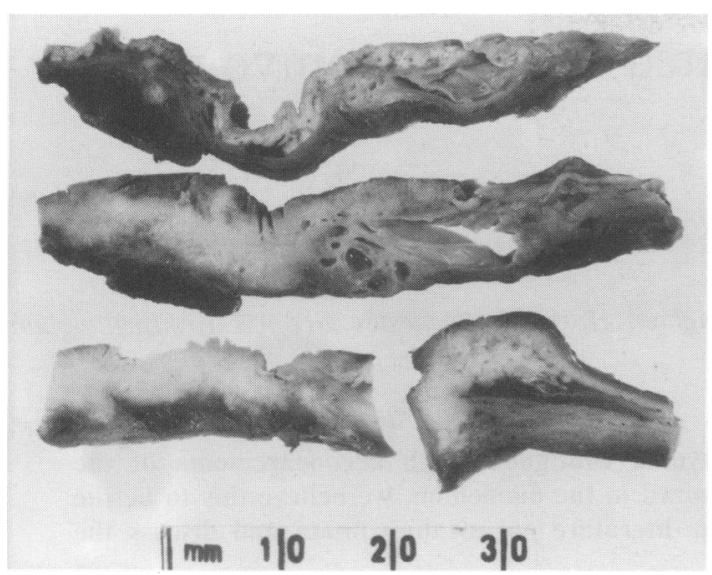

Figure 1 Cut surface of the carcinoma and adenomyoma. Carcinoma to the left and across the lower slices. Cystic spaces extending on to the serosa within the right half of the upper two slices.

mitoses, epithelial multilayering and complex crowded and papillary gland formation (Figure 3).

\section{Discussion}

Gastric adenomyomata were first described by Magnus-Alsleben in $1903 .^{2}$ They are generally accepted to be rare gastric tumours, with only 37 cases reported to date,* although it has recently

*The authors will provide a full list of references on request. been suggested that they may be more common. The diagnosis of adenomyomata encompasses a spectrum of histological features including ductal tissue, smooth muscle and glandular tissue which in some cases may resemble Brunner's glands or pancreatic acini. If there is a predominance of pancreatic tissue then the term 'pancreatic heterotopia' or 'pancreatic rest' is more appropriate. These latter lesions occur more frequently than other types of adenomyomata, with a reported incidence of 0.6 to $5.6 \%,{ }^{3}$ the majority being found in the upper gastrointestinal tract within 5 to $6 \mathrm{~cm}$ of the pylorus, many within the stomach itself. There has been considerable debate regarding both the histological classification and histogenesis of gastric adenomyomata. Clarke proposed that they should be regarded as hamartomata ${ }^{4}$ while others favoured a heterotopia ${ }^{5}$. At present, the histogenesis of gastric adenomyomata is unknown, although most reports consider them to be of developmental origin.

They principally involve the distal part of the stomach (antrum $85 \%$, pylorus $15 \%$ ); 1 although the age range for reported cases is 8 weeks to 81 years, the majority of the cases occur in the fourth to sixth decades and usually present, as did our case, with non-specific symptoms such as intermittent epigastric pain, nausea and vomiting, although they may cause pyloric obstruction. They are also reported as a coincidental finding in patients operated on for gastric ulcer and hypertrophic pyloric? stenosis. Unlike similar lesions in the duodenum, they have not previously been reported in association with carcinoma. In contrast, there have been three previously reported cases of malignancy

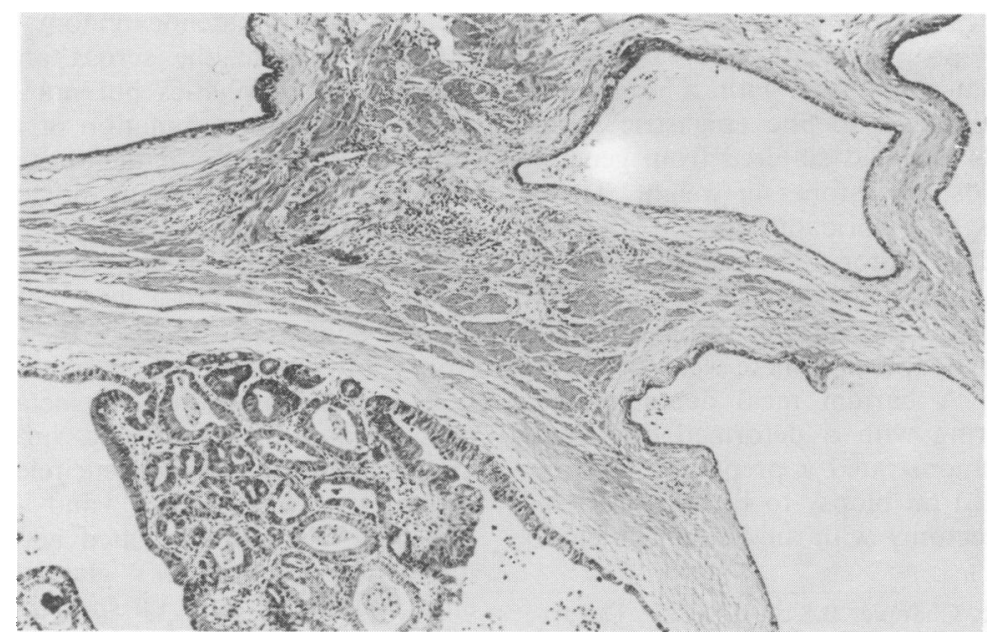

Figure 2 Cystic spaces surrounded by muscle. Intracystic glandular and papillary proliferation within the lower half of the field $(\mathrm{H} \& \mathrm{E} \times 19.5)$. 


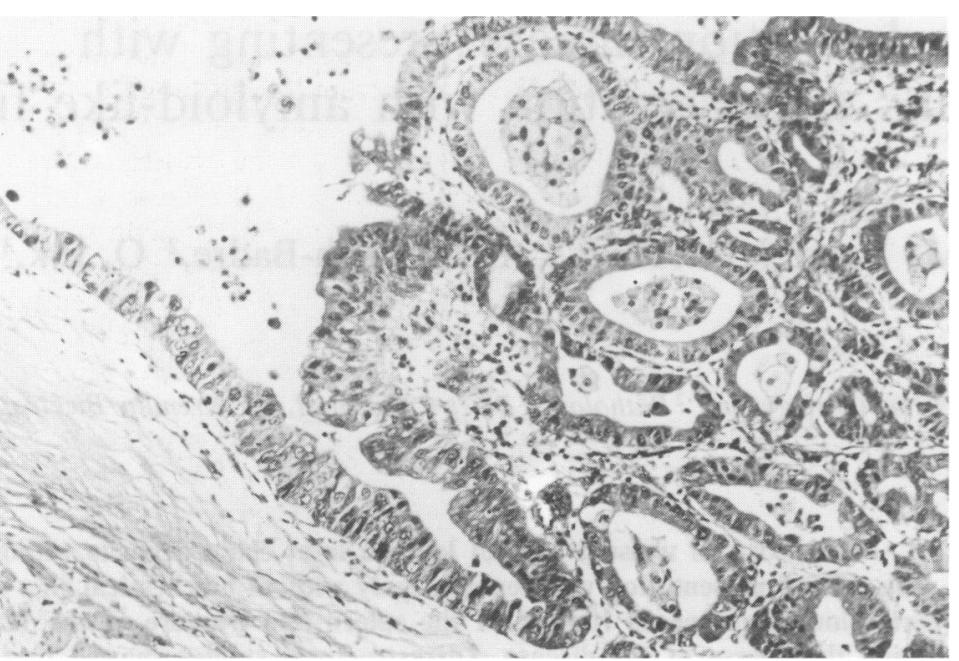

Figure 3 Highly atypical epithelium lining a large cyst, with atypical glandular proliferation and back-toback crowding (H\& $\mathrm{E} \times 71.5)$.

occurring in gastric pancreatic heterotopia, where the carcinoma was considered to arise from the pancreatic tissue. ${ }^{3}$

The problem of malignancy arising in cystic lesions of the stomach becomes even more complex when one considers the condition gastritis cystica profunda. This is a diffuse lesion characterized by submucosal cysts surrounded by smooth muscle, which communicate with the gastric surface mucosa, which is often affected by gastritis, and has a well recognized association with gastric adenocarcinoma. ${ }^{6}$

We therefore suggest that glandular and cystic intramural lesions of the stomach are a heterogeneous group and whilst some are probably deve-

\section{References}

1. Zarling, E.J. Gastric adenomyoma with coincidental pancreatic rest: a case report. Gastrointest Endosc 1981, 27: $175-177$.

2. Magnus-Alsleben, E. IV. Adenomyome des pylorus. Virchows Arch [A] 1903, 173: 137-156.

3. Goldfarb, W.B., Bennett, D. \& Monafo, W. Carcinoma in heterotopic gastric pancreas. Ann Surg 1963, 158: 56-58. lopmental in origin, others such as gastritis cystica profunda may well be acquired. In addition, heterotopia should be distinguished from true adenomyomata. The association of gastric carcinoma and gastritis cystica profunda is well recognized; its association with pancreatic heterotopia has also previously been reported, but we believe that our case is the first report of adenomyoma of the stomach in association with gastric carcinoma.

\section{Acknowledgements}

We are grateful to P. Nar, M.J. Chard and C. Davies for technical assistance and E.S. White for typing the manuscript.

4. Clarke, B.E. Myoepithelial hamartomata of the gastrointestinal tract. Arch Pathol 1940, 30: 143-152.

5. Lasser, A. \&. Koufman, W.B. Adenomyoma of the stomach. Dig Dis Sci 1977, 22: 965-969.

6. Franzing, G. \& Novelli, P. Gastritis cystica profunda. Histopathology 1981, 5: 535-547. 